\title{
History of the Modern Probability Philosophy
}

\author{
Seifedine Kadry \\ American University of the Middle East, Egaila, Kuwait \\ Email: skadry@gmail.com
}

Received 27 January 2014; revised 27 February 2014; accepted 5 March 2014

Copyright (c) 2014 by author and Scientific Research Publishing Inc.

This work is licensed under the Creative Commons Attribution International License (CC BY).

http://creativecommons.org/licenses/by/4.0/

C. (†) Open Access

\section{Abstract \\ The purpose of the paper is to introduce the evolution of modern probability from its birth in the seventeenth century onwards.}

Keywords

Probability; History; Modern Probability

\section{What Is Probability?}

Today probability is understood as a quantitative notion, expressed by a real number ranging in the interval between 0 and 1 . Probability values are determined in relation to a given body of evidence, conveying information that is relevant to the facts of which the probability is to be estimated.

\section{The Notion of Probability}

The notion of probability so conceived is reputed to have come into existence in the decade around 1660, in connection to the work of Blaise Pascal and Pierre Fermat.

Early on, probability was mainly taken to refer to the approval of an opinion on the part of experts. In an authoritative study focused on Thomas Aquinas, Edmund Byrne shows how in the Middle Ages probability was not so much linked to empirical evidence, as it concerned approval by people widely recognized as upright and respectable (Byrne, 1968). In the context of medieval thought probability, as opposed to truly scientific knowledge namely the kind of knowledge amenable to demonstration—assumes its basic meaning as indicative of the relationship between an opinion and an argument (probatio) or arguments brought forth in its favor (hence, "provable” or perhaps "approvable”). Byrne (Byrne, 1968) detects in Aquinas' work the coexistence of two different usages of the term "probability", which is taken sometimes to refer to propositions, and sometimes to 
contingent facts, more precisely to the frequency with which the latter occur. As pointed out by Ian Hacking in The Emergence of Probability (Hacking, 1975), this duality of meaning is peculiar to the notion of probability, and persisted in the passage from the "prehistory" to the "history" of this notion, which passage was characterized by the fact that probability ceased to be associated with the opinion of experts, and started to represent the degree of certainty to be ascribed to an event whose outcome is uncertain on the basis of the available information, taken to include evidence based on facts.

\section{Birth of Probability}

The birth of probability is often associated with an anecdote, reported by a number of sources as authoritative as Gottfried Wilhelm Leibniz and Simeon Denis Poisson. The latter claimed that "A problem about games of chance proposed to an austere Jansenist by a man of the world was the origin of the calculus of probabilities" (Poisson, 1837).

The gambler in this story is the French gentleman Chevalier de Mere, a conspicuous figure at the court of Louis XIV, while the "austere Jansenist" is the prominent scientist and philosopher.

Blaise Pascal (Pascal, 1670), who was converted to the Jansenist doctrine and in the last years of his life devoted great effort to defend it against disbelievers. The problems posed by Mere were of the following sort: "in throwing two dice, how many tosses are needed to have at least an even chance of getting double-six?”, and "how should one divide the stakes among the players, if a game is interrupted after a certain number of trials?". To solve the problems, Pascal involved the leading mathematician Pierre Fermat (Fermat, 1679), and in 1654 the two exchanged a correspondence, which is considered to be the cradle of modem theory of probability. In that same year, Pascal himself worked out his ideas on the matter in "Traite du triangle arithmetique", published posthumously in 1665 (Pascal, 1665).

To be sure, problems of the kind were in no way new, as they had been analyzed and given solutions early on. What is new to the treatment of Pascal and Fermat is their systematic approach, which paved the way to the search for universal rules detached from particular problems, and valid for all chance phenomena. As a matter of fact, before Pascal and Fermat the modem notion of probability cannot be said to be totally absent. Various authors, including Luca Pacioli, Gerolamo Cardano, Niccolo Tartaglia and Galileo Galilei had already studied a clutch of similar problems, coming up with insightful solutions. Moreover, there is a widespread tendency to hold that in the Renaissance period the so-called "low sciences", including medicine, alchemy, astrology and the earth sciences, contributed to the emergence of statistics and probability.

Going back to Pascal, it is noteworthy that he was so deeply convinced of the overarching power of probability that he did not hesitate to apply it to God's existence.

The argument known as "Pascal's wager"-contained in the famous Pensees (Pascal, 1670) is precisely meant to support belief in God by means of considerations grounded on probability and utility. Pascal's wager can be summarized as follows: betting on God's existence - and therefore acting as if God existed-is reasonable, because it maximizes expected good. For, if we, totally undecided on whether to evaluate God's existence as more or less probable than God's non-existence, assigned to it a probability of one half, we should bet on it anyway, in view of the expectation of two lives in place of one.

The bet would be convenient even if we assigned an infinitely small probability to God's existence, because this is counterbalanced by the expected value of an eternal life, which can be considered infinite. Pointing out the historical importance of this argument, Hacking maintains that the relevant passages of Pascal's Pensees had an important byproduct: they showed how aleatory arithmetic could be part of a general "art of conjecturing".

They made it possible to understand that the structure of reasoning about games of chance can be transferred to inference that is not founded on any chance setup.

Moreover, he observes that "the popularity of the Pensees made it a familiar fact that games of chance could serve as models for other problems about form of decision under uncertainty. Pascal's wager testifies to the fact that considerations of utility and bets had been an essential component of the notion of probability since the beginnings of its history. More evidence in support of this claim is offered by the work of another pioneer of modem probability. One year after Pascal and Fermat corresponded, the Dutch scientist Christiaan Huygens (Huygens, 1940), during a journey to Paris, met Chevalier de Mere at the house of the Duke of Roannez, a good friend of Pascal, and came to know the work of Pascal and Fermat. Back in Holland, he started working on 
probability problems, and two years later published the first treatise on probability, De ratiociniis in aleae ludo (Huygens, 1940).

The distinctive feature of Huygens' work is the extensive use of what is today called "mathematical expectation". This is based on the idea that the value of a game depends both on the probability of obtaining certain outcomes and the gain associated with each of them.

In the second half of the seventeenth century, the study of probability progressed enormously, also thanks to the combinatorial calculus, and progressively widened its scope of application. Great impulse to such development came from the application of the notion of arithmetic mean to such data as natality and mortality tables, registered for annuities and insurance policies. An important contribution to advancement in this field came from the publication in 1662 of the Natural and Political Observations Made upon the Bills of Mortality by the London businessman John Graunt (Graunt, 1662), and of another essay on the same topic by the Dutch mathematician and politician Jan de Witt. A valuable contribution also came from Huygens, who devised some measures of life expectancies (Huygens, 1940).

The extensive use of statistical measures soon pervaded other fields, like medical practice, legal decisions, and, last but not least, the physical and biological sciences.

Gottfried Wilhelm Leibniz (Leibniz, 1704) worked intensively on the application of combinatorics to legal problems, laying great stress on the importance of probabilistic reasoning. As pointed out by Lorraine Daston in her Classical Probability in the Enlightenment Leibniz combatted Locke"s nominalism (Daston, 1988) by defending the reliability of probabilistic reasoning.

\section{Jakob Bernoulli and Direct Probability}

A decisive contribution to the development of the notion of probability came from the work of various members of the Bernoulli family, of Dutch origin but who later settled in Basel. Bernoulli's result (Bernoulli, 1713) is based on the concept of stochastic independence, which for the first time receives an unambiguous definition. The theorem holds for binary processes, namely processes that admit of two outcomes-like "heads" and "tails", or "presence" and "absence" of a certain property. Bernoulli's work also sheds light on the relationship between probability and frequency, by keeping separate the probability and the frequency with which the events of the considered dichotomy can theoretically occur in any given number $\mathrm{n}$ of experiments, and sets the probability distribution over possible frequencies: $0,1,2, \ldots, \mathrm{n}$, usually called binomial distribution.

\section{Thomas Bayes and Inverse Probability}

During the second half of the eighteenth century, an important result was obtained by Thomas Bayes (Bayes, 1763), a Nonconformist minister at Tunbridge Wells, near London, elected Fellow of the Royal Society in 1742.

Bayes spells out a method for assessing inverse probability, or the probability to be assigned to a hypothesis on the ground of available evidence. Whereas by direct probability one goes from the known probability of a population to the estimated frequency of its samples, by inverse probability one goes from known frequencies to estimated probabilities. Inverse probability is sometimes called "probability of causes", because it enables us to estimate the probabilities of the causes underlying an observed event. The analysis of inverse probability, later carried on by Laplace, was to become a major field within probability theory.

\section{Probability and Social Mathematics: Condorcet and Quetelet}

In addition to the progress brought to the field by the Bernoulli, Bayes, and many others, probability considerably widened its range of application in the eighteenth century, particularly in the realm of the moral and political sciences.

An outstanding representative of such a tendency was the French mathematician Marie-Jean-Antoine-Nicolas Caritat, Marquis de Condorcet (Dale, 1991).

Condorcet assumed that enlightened men who naturally reckoned by inverse probabilities would always agree with one another: right reason admitted only one answer to any question. By public instruction in the results, if not the mathematical theory, of the calculus of probabilities, the circle of reasonable consensus could be widened to include everyone. 


\section{References}

Byrne, E. (1968). Probability and Opinion. Study in the Medieval Presuppositions of Post Medieval Theories of Probability. The Hague: Martinus Nijhoff.

Bernoulli, J. (1713). Ars conjectandi, opus posthumum. Accedit tractatus de seriebus infinitis, et epistola gallicè scripta de ludo pilae reticularis. Basel: Impensis Thurnisiorum, fratrum.

Bayes, T. (1763). An Essay towards Solving a Problem in the Doctrine of Chances. Philosophical Transactions, 53, 370-418.

Daston, L. (1988). Classical Probability in the Enlightenment. Princeton: Princeton University Press.

Dale, A. (1991). A History of Inverse Probability. From Thomas Bayes to Karl Pearson. New York: Springer.

Fermat, P. (1679). Varia Opera Mathematica. Toulouse: Joannis Pech.

Graunt, J. (1662). Natural and Political Observations Made upon the Bills of Mortality. London: Martin.

Huygens, C. (1944). Oeuvres completes de Christiaan Huygens (vol. 22). The Hague: Dutch Academy of Sciences.

Hacking, I. (1975). The Emergence of Probability. Cambridge: Cambridge University Press.

Leibniz, G. W. (1704). Nouveaux essais sur l'entendement humain. Paris: Groupe Flammarion.

Poisson, S.-D. (1837). Recherches sur fa probabilite des jugements en matiere criminelle et en matiere civile. Precedees des regles gemirales du calcul des probabilitis. Paris: BacheJier.

Pascal, B. (1670). Pensees. Paris: Port Royal.

Pascal, B. (1665). Traite du triangle arithmetique. Paris. 